\title{
Optimal Choice of Capacity, Toll and Government Guarantee for Build- Operate-Transfer Roads under Asymmetric Cost Information
}

\author{
Shasha Shi ${ }^{\mathrm{a}}$, Yafeng Yin $^{\mathrm{b}, 1}$ and Xiaolei Guo ${ }^{\mathrm{c}}$ \\ ${ }^{a}$ School of Business, Central South University, Changsha, P.R. China \\ ${ }^{\mathrm{b}}$ Department of Civil and Coastal Engineering, University of Florida, Gainesville, FL, United States \\ 'Odette School of Business, University of Windsor, Ontario, Canada
}

\begin{abstract}
The private provision of public roads via the build-operate-transfer (BOT) mode has been increasingly used around the world. By viewing a BOT contract as a combination of road capacity, toll and government guarantee, this paper investigates optimal concession contract design under both symmetric and asymmetric information about the marginal maintenance cost of the private investor. Under asymmetric information, the government guarantee serves as an instrument to induce the private investor to reveal his true cost information. Compared with the situation under symmetric information, the government will suffer a loss of social welfare; the private investor will charge a higher toll that increases in his reported marginal maintenance cost, and specify a lower capacity that decreases with the reported cost. The results also show that the private investor obtains extra information rent beyond the reservation level of return and the rent decreases with his reported cost. However, the resulting volume-capacity ratios of the BOT road under both information structures are the same.
\end{abstract}

Keywords: Build-operate-transfer, road capacity, pricing, government guarantee, concession contract and asymmetric cost information

\section{Introduction}

Engaging private investors and entrepreneurs in constructing and operating transportation facilities has emerged as one of the most viable options for transportation infrastructure provision, as governments are facing tightening fiscal budgets and private investors could build and operate roads at lower costs than the government sector. Moreover, according to the self-financing theorem, if a new road is privately provided as an "add-on" to an existing road network, and it is to be paid by road users who are willing to patronize it, all its cost will be covered by the toll revenue and all the stakeholders of this private road would gain related benefits (e.g., Yang and Meng, 2000). Perhaps for all these reasons, governments have increased their reliance on private

\footnotetext{
${ }^{1}$ Corresponding author. Tel.: 352-294-7805; Email: yafeng@ufl.edu
} 

which a private investor would build and operate a new road at his own expense and in turn receive the revenue from charging road tolls for a pre-defined concession period and then transfer it to the government sector. As such, BOT roads involve two critical stakeholders: the government and private investors. For the former, social welfare of this new road is of great concern, while the latter are interested in its profitability, which is a tradeoff between the profit they could receive from operating it and the risk they must assume. The allocation between social welfare and private profit depends on a long-term concession contract between the government and the private investor. A typical concession contract includes several fundamental components such as the concession period, road capacity, toll rates, and government guarantee. Each of them is critical in determining whether a BOT road is socially feasible and profitable to the private investor.

A number of previous studies have examined various issues related to BOT road projects. Some are dedicated to concession contract schemes and the discussions have primarily focused on the choice of capacity and toll charge to make a tradeoff between social welfare and private profit. In a general equilibrium context, Viton (1995) looked into the profitability of a BOT road in a network with a single BOT road and a single parallel public road. Yang and Meng $(2000,2002)$ formulated a bi-level programming model to analyze the profitability and social welfare gain of a single BOT road in a network, and calculated the optimal combination of toll and capacity under different conditions. Chen et al. (2003) integrated risk analysis and network optimization into a stochastic optimization model, and analyzed the optimal combination of toll and capacity under demand uncertainty. Guo and Yang (2009) designed the optimal concession contract, a combination of concession period, toll charge and capacity, to maximize social welfare, while satisfying the profit constraint of private investors. Tan et al. (2009) extended the study by considering road deterioration and maintenance and found that an optimal pricing policy requires toll to increase over time to reduce traffic load due to the time-increasing and load-increasing maintenance cost. Tan and Yang (2012) further considered demand uncertainty and investigated the full and partial flexibility of concession contract based on ex post contract adjustment. In a related effort, building upon a property of constant volume-capacity ratio of private toll roads (e.g., Xiao et al., 2007; Wu et al., 2011a; and Wang and Meng, 2013), Wu et al. (2011b) formulated and solved a tri-level program to optimally select highway projects for BOT development to improve social welfare while ensuring the projects marketable.

As private investors will gain some monopoly rights over road infrastructure assets during a predetermined concession period, the government sector may need to protect the public interest by imposing regulations. Chen and Subprasom (2007) pointed out that both the price control regulation and equity regulation would cause a BOT road to be financial infeasible. Tan et al. (2010) investigated a variety of regulatory regimes to analyze the behavior of private investors, 

outcomes, while both the demand and markup charge regulations lead to Pareto-optimal outcomes.

Lastly, a few attempts have been made on auction mechanisms of BOT roads. Engel et al. (2001) proposed a new auction mechanism for highway franchise based on the least present value of revenue, and found that the mechanism would resolve the winners' curse and suppress ex post opportunism of the regulator and concessionaire as well as opportunistic behaviors of deliberate underbidding and contract renegotiation. Nombela and Rus (2004) proposed a franchising mechanism based on flexible term contracts and bids for total net revenue and maintenance costs, and suggested that this mechanism, compared with a fixed term mechanism, would select more efficient concessionaires. Verhoef (2007) studied welfare impacts of franchising regimes for congestible highways, and found that the patronage-maximizing auction is no longer optimal when considering a simple two-link network with one BOT road and the other unpriced parallel or serial road. Ubbels and Verhoef (2008) analyzed the welfare consequences of four different auction rules and reported that a bid with the minimization of price on the tolled road leads to very promising results in terms of welfare for auctions without subsidies; when allowing for subsidies, the best bid appears to involve the minimization of generalized travel costs comprising the toll on the new road and the subsidy divided by total traffic demand. Vassallo (2010) evaluated the effect that the discount rate established by the government in the bidding terms has on traffic risk allocation, and revealed that the lower the discount rate is, the larger the traffic risk allocated to the concessionaire will be.

A critical assumption made in most of these previous studies is that the government has complete information about private investors and thus can design concession contract schemes accordingly. This is rarely true in practice where private investors often possess information advantage regarding their efficiency and capability (Auriol and Picard, 2009). Specifically, the construction and maintenance costs of a particular road are affected by a number of factors such as market price of materials, labor cost, traffic loads, inflation and weather conditions, which are very difficult for both the government and the private investor to pre-specify (Small et al, 1989; Michael et al, 2015). However, the costs also depend on the choice and application of technology by the private investor, his pursuit of innovation in materials, processes and management, and his experience with other relevant projects (Gunter and Alberto, 1999). Therefore, the government sector is exposed to information asymmetry with respect to the efficiency and capability of the private investor. The government also suffers from another type of information asymmetry due to hidden actions by the private investor after a contract has been signed (Bolton and Dewatripont, 2005).

The information asymmetry between the government and the private investor has a significant impact on the efficiency of a concession contract. Ignorance of such information asymmetry can make it difficult for the government to fulfill a contract at the operation stage, and contract 
renegotiation consequently occurs. Recognizing that the concession contract variables determined in the complete information context do not necessarily yield optimal outcomes, we relax in this paper the complete information assumption and derive the optimal decision for the government on the selection of capacity, toll and guarantee. In line with Guo and Yang (2008), the concession period is assumed to be pre-determined. The government guarantee is considered in this paper as an incentive scheme in forming a BOT contract under asymmetric information. We firstly formulate a social welfare maximizing problem to optimize contract variables as well as ensuring the private investor to receive a reservation level of utility, which can be viewed as the symmetric information model. We show that if its solution is applied to the asymmetric information context, the private investor would have the motivation to overstate his true cost information to receive more profit than the reservation level. Without observing the true cost of the private investor during the contract negotiation period, the government will not be able to identify those optimal concession contract variables. We thus further analyze the optimal concession contract under asymmetric cost information by taking into account both the reservation utility level and the truth-telling mechanism. A strategy is proposed for the government to set separate contracts corresponding to the private investor's reported cost information, while allowing the private investor to choose a preferable combination of road capacity, toll and government guarantee by himself based on his true cost. Comparing the solutions to optimal BOT problems under the symmetric and asymmetric information structures, we find that the optimal traffic demand and road capacity under asymmetric information are no more than the ones under symmetric information. However, the resulting volume-capacity ratios under both information structures are the same. Among others, we also find that the asymmetricinformation toll is no less than the symmetric-information toll, and the private investor obtains the information rent by owning private information, which results in a loss in social welfare.

The remainder of this paper is organized as follows. We begin with introducing basic assumptions and considerations in Section 2 and discuss the optimal concession contract schemes for BOT roads under symmetric information. Section 3 discusses the optimal BOT problem under asymmetric cost information. A social welfare maximizing problem is formulated with both the individual rationality and incentive compatibility constraints. Meanwhile, we compare the solutions under both information structures in Section 4. Section 5 presents a numerical example to elucidate our results. Finally, Section 6 concludes the paper.

\section{BOT Concession Contract Model under Symmetric Information}

Consider that a government attempts to delegate a private investor to build and operate a new road with a pre-determined concession period. We investigate the resulting social welfare and profit of the new road, which is a function of its capacity and toll rate. In addition, we propose for the government to guarantee a certain amount of payment to the private investor. In practice, governments often employ a minimum revenue guarantee to ensure the profit from the new road 
to exceed a certain level. It is often an optional payment to help hedge against revenue risk associated with, e.g., demand uncertainty, and thus would encourage private investors to participate (Ashuri et al., 2012). To facilitate the presentation of our key idea, we assume in this paper a deterministic demand function and do not consider other risks. As such, the government guarantee considered here is different from the conventional one. As we will demonstrate in Section 3, combined with road capacity and toll rate, it serves as an instrument to induce the private investor to reveal his true cost information rather than encouraging him to participate.

Let $y \geq 0$ be the capacity of the new road and $q \geq 0$ be the traffic demand, both measured in the number of vehicles per unit time. Let $B(q)$ be the inverse demand function. Moreover, $B(q)=$ $p+\beta t(q, y)$, where $p$ is the toll rate and $\beta$ is the value of time of road users, who are assumed to be homogenous, and $t(q, y)$ is the travel time of this new road, which is a function of traffic demand $q$ and road capacity $y$. Subsequently, we derive a price function $p(q, y)=B(q)-$ $\beta t(q, y)$. Let $c(q, y)$ be the road construction and maintenance cost function and $c(q, y)=$ $I(y)+\theta q$, where $I(y)$ includes the amortized construction cost and capacity-related maintenance cost, and $\theta q$ is the annual demand-related maintenance cost. We assume in this paper that $I(y)$ is the same for all private investors and is known to the government while $\theta$, the marginal maintenance cost, varies within an interval $\left[\theta_{0}, \theta_{1}\right]$ and may differ from one investor to another. The parameter $\theta$ may represent the technology used by a private investor to operate and maintain the BOT road. A lower $\theta$ can be expected for an efficient private investor who is capable of applying more advanced technology. In contrast, higher values of $\theta$ can be assumed for those less efficient private investors. We further note that information asymmetry also arises for the construction cost and its impact on the optimal BOT contracts may be different, because the construction cost is capacity dependent while the maintenance cost is demand dependent. However, to facilitate the presentation of our key idea, we only consider the asymmetric information of marginal maintenance cost in this paper.

Let $R(q, y, g)$ and $W(q, y, g)$ be the utility function of the private investor and the government respectively. In a deterministic context, they are simply the private profit and social welfare functions. For the former, we have the following:

$$
R(q, y, g)=q p(q, y)-[I(y)+\theta q]+g=q B(q)-q \beta t(q, y)-[I(y)+\theta q]+g
$$
where $g$ denotes the government guarantee. The first term represents the revenue obtained by the private investor; the second is the total construction and maintenance cost while the last is the government guarantee, a constant payment or subsidy that the government will provide to the private investor. Therefore, the private profit function essentially consists of two parts: the project profit $\overline{\bar{R}}(q, y)$ and the government guarantee $g$, i.e., $R(q, y, g)=\overline{\bar{R}}(q, y)+g$.

We further define the social welfare function of the government sector as follows:

$$
W(q, y, g)=\int_{0}^{q} B(\omega) d \omega-q B(q)+\alpha R(q, y, g)-g
$$


where $\alpha$ is a weighting factor and $0<\alpha<1$.

Equation (2) consists of the consumers' surplus and the weighted producer's surplus. The weighting factor $\alpha$ given to the producer's surplus reflects the situation where, e.g., not all the private investors reside in the government's jurisdiction whereas all road users do (e.g., Bailey, 1976 and Bower, 1981).

Substituting (1) into (2) yields the following:

$$
\begin{aligned}
W(q, y, g)= & \left\{\int_{0}^{q} B(\omega) d \omega-(1-\alpha) q B(q)-\alpha q \beta t(q, y)-\alpha[I(y)+\theta q]\right\} \\
& -(1-\alpha) g
\end{aligned}
$$

We further note that an additional social cost may occur when the government provides a guarantee because each dollar transferred to the private investor may cost more than one dollar to the society (de Palma et al., 2007). To capture this, a coefficient can be added to be associated with the government guarantee. Consequently, the government guarantee component in Equation (3), i.e., $(1-\alpha) g$, can be rewritten as $\alpha^{\prime} g$ where $\alpha^{\prime}(>0)$ encapsulates both factors, i.e., the discount of the producer's surplus and the social cost of the government guarantee. Such a change would not change the analyses and conclusions in this paper. For simplicity, we hereinafter assume the coefficient reflecting the social cost to be one.

In Equation (3), there are three variables, i.e., $q, y$, and $g$. Alternatively, $q$ can be viewed as an indirect control variable via another direct control variable $p$, the toll rate. Namely, for a given road capacity $y$ and government guarantee $g, q$ can be achieved by choosing an appropriate toll rate.

We now consider the symmetric information structure where the government sector has the full information of the private investor's cost function including his marginal maintenance cost $\theta$. From the government's perspective, we now formulate the BOT concession contract problem as a social welfare maximizing problem:

$$
\begin{aligned}
& \max W(q, y, g)=\int_{0}^{q} B(\omega) d \omega-(1-\alpha) q B(q)-(1-\alpha) g-\alpha q \beta t(q, y)-\alpha[I(y)+\theta q] \\
& \text { s.t. } \quad R(q, y, g)=q B(q)-q \beta t(q, y)-[I(y)+\theta q]+g \geq \tilde{P} \\
& \quad q \geq 0, \quad y \geq 0, \quad g \geq 0
\end{aligned}
$$

In the above, the first constraint is called as the individual rationality (IR) constraint, requiring that the profit should be no less than a reservation level $\widetilde{P}$. Because the private investor may have another investment opportunity available that awards him a reservation level of utility $\widetilde{P}$, the 
government must ensure that the private investor obtains at least this reservation level for his willingness to participate (Varian, 1992).

For simplicity, we will not consider the non-negative constraints of decision variables $q, y$ and $g$, as they are often not binding. We further assume that the feasible region given by the IR constraint is not empty. For the uniqueness of an optimal solution to the BOT problem (4), we make additional assumptions on $B(q), t(q, y), c(q, y)$ and $I(y)$.

Assumption 1: The inverse demand function $B(q)$ is a strictly decreasing and differentiable function of $q$ for $q \geq 0$;

Assumption 2: For $q \geq 0$ and $y \geq 0$, the travel time function $t(q, y)$ is a differentiable and strictly convex function of $q$ and $y$ respectively. The function strictly decreases with $y$ and strictly increases with $q$. It is homogeneous of degree zero in $q$ and $y$.

Assumption 3: The capacity-related cost function $I(y)=l y$, where $l$ is the constant marginal construction cost.

The above assumptions have been widely adopted in the literature and are often valid. However, to ensure the concavity of the social welfare function (3) and private profit function (1), we make one additional assumption as follows:

Assumption 4: $B(q)$ is convex and $q B(q)$ is concave for $q \geq 0$. Moreover, the weighting factor of the producer's surplus $\alpha \geq 0.5$.

Assumption 4 requires that the inverse demand function $B(q)$ is convex and that the total traffic cost of road users $q B(q)$ is concave (Ziya et al. 2004; Guo and Yang, 2005). Both hold for some common types of inverse demand functions, i.e., linear, exponential and negative power functions. This is to ensure that the private profit function is concave function of $q$. Meanwhile, Assumption 4 requires that the weighting factor is no less than 0.5 , which can further ensure the concavity of the social welfare function.

With assumptions 1 to 4, the BOT concession contract problem is a concave maximization problem with a convex feasible region, for which the Karush-Kuhn-Tucker (KKT) conditions are both necessary and sufficient.

Let $\left(q^{*}, y^{*}, g^{*}\right)$ be an optimal solution to the BOT problem. Let $\left(q_{1}, y_{1}\right)$ be the optimal solution that maximizes $R\left(q, y, g^{*}\right)$, and $\left(q_{0}, y_{0}\right)$ be the optimal solution that maximizes $W\left(q, y, g^{*}\right)$ without the IR constraint. For the lack of better terms, we call the maximization of $R\left(q, y, g^{*}\right)$ as the private road problem, and the maximization of $W\left(q, y, g^{*}\right)$ as the public road problem. Since both problems are unconstrained concave maximization problems, we have their optimal conditions as follows: 


$$
\begin{aligned}
& \frac{\partial R\left(q_{1}, y_{1}, g^{*}\right)}{\partial q}=\frac{\partial \overline{\bar{R}}\left(q_{1}, y_{1}\right)}{\partial q}=B\left(q_{1}\right)+q_{1} B^{\prime}\left(q_{1}\right)-\beta t\left(q_{1}, y_{1}\right)-\beta q_{1} \frac{\partial t\left(q_{1}, y_{1}\right)}{\partial q}-\theta=0 \\
& \frac{\partial R\left(q_{1}, y_{1}, g^{*}\right)}{\partial y}=\frac{\partial \overline{\bar{R}}\left(q_{1}, y_{1}\right)}{\partial y}=-\beta q_{1} \frac{\partial t\left(q_{1}, y_{1}\right)}{\partial y}-l=0 \\
& \frac{\partial W\left(q_{0}, y_{0}, g^{*}\right)}{\partial q}=-q B^{\prime}\left(q_{0}\right)+\alpha B\left(q_{0}\right)+\alpha q_{0} B^{\prime}\left(q_{0}\right)-\alpha \beta t\left(q_{0}, y_{0}\right)-\alpha \beta q_{0} \frac{\partial t\left(q_{0}, y_{0}\right)}{\partial q}-\alpha \theta \\
& =\alpha \frac{\partial \overline{\bar{R}}\left(q_{0}, y_{0}\right)}{\partial q}-q_{0} B^{\prime}\left(q_{0}\right)=0 \\
& \frac{\partial W\left(q_{0}, y_{0}, g^{*}\right)}{\partial y}=-\alpha \beta q_{0} \frac{\partial t\left(q_{0}, y_{0}\right)}{\partial y}-\alpha l=0
\end{aligned}
$$

Comparing the optimal solutions to the BOT road, private road and public road problems, we derive Proposition 1 as follows:

Proposition 1. It holds for the optimal solution $\left(q^{*}, y^{*}, g^{*}\right)$ that

$$
\begin{aligned}
& \text { (a) } q_{1}<q^{*}<q_{0} \\
& \text { (b) } y_{1}<y^{*}<y_{0} \\
& \text { (c) } g^{*}=\widetilde{P}+I\left(y^{*}\right)+\theta q^{*}-q^{*} p\left(q^{*}, y^{*}\right)
\end{aligned}
$$

Proof: With $\lambda$ being the KKT multiplier associated with the IR constraint (4), we derive the KKT conditions of the BOT problem as follows:

$$
\begin{aligned}
& \frac{\partial W\left(q^{*}, y^{*}, g^{*}\right)}{\partial q}+\lambda \frac{\partial\left[R\left(q^{*}, y^{*}, g^{*}\right)-\tilde{P}\right]}{\partial q}=\alpha \frac{\partial \overline{\bar{R}}\left(q^{*}, y^{*}\right)}{\partial q}-q^{*} B^{\prime}\left(q^{*}\right)+\lambda \frac{\partial \overline{\bar{R}}\left(q^{*}, y^{*}\right)}{\partial q} \\
& =-q^{*} B^{\prime}\left(q^{*}\right)+\alpha B\left(q^{*}\right)+\alpha q^{*} B^{\prime}\left(q^{*}\right)-\alpha \beta t\left(q^{*}, y^{*}\right)-\alpha \beta q^{*} \frac{\partial t\left(q^{*}, y^{*}\right)}{\partial q}-\alpha \theta \\
& +\lambda\left[B\left(q^{*}\right)+q^{*} B^{\prime}\left(q^{*}\right)-\beta t\left(q^{*}, y^{*}\right)-\beta q^{*} \frac{\partial t\left(q^{*}, y^{*}\right)}{\partial q}-\theta\right]=0 \\
& \begin{aligned}
\frac{\partial W\left(q^{*}, y^{*}, g^{*}\right)}{\partial y}+ & \lambda \frac{\partial\left[R\left(q^{*}, y^{*}, g^{*}\right)-\tilde{P}\right]}{\partial y}=\frac{\partial W\left(q^{*}, y^{*}, g^{*}\right)}{\partial y}+\lambda \frac{\partial \overline{\bar{R}}\left(q^{*}, y^{*}\right)}{\partial y} \\
& =-(\alpha+\lambda)\left[\beta q^{*} \frac{\partial t\left(q^{*}, y^{*}\right)}{\partial y}+l\right]=0
\end{aligned}
\end{aligned}
$$


$R\left(q^{*}, y^{*}, g^{*}\right)-\tilde{P} \geq 0$

$\lambda \geq 0$

$\lambda\left[R\left(q^{*}, y^{*}, g^{*}\right)-\tilde{P}\right]=0$

From (11), $\lambda=1-\alpha$. As $0.5 \leq \alpha<1$, we have $\lambda>0$, which indicates that IR constraint is binding at the optimal solution, i.e., $R\left(q^{*}, y^{*}, g^{*}\right)=q^{*} B\left(q^{*}\right)-q^{*} \beta t\left(q^{*}, y^{*}\right)-\left[I\left(y^{*}\right)+\right.$ $\left.\theta q^{*}\right]+g^{*}=\tilde{P}$. Thus, Proposition 1 (c) is proved.

Comparing (6), (8) and (10), we can infer that the relationship between the optimal traffic demand and road capacity is the same for the BOT road, private road and public road problems. We thus define an implicit function as $y=y(q)$, whose derivative is $y^{\prime}(q)=-\frac{\frac{\partial t(q, y(q))}{\partial y}+q \frac{\partial^{2} t(q, y(q))}{\partial q \partial y}}{q \frac{\partial^{2} t(q, y(q))}{\partial y^{2}}}$. Since the travel time function is homogeneous of degree zero, it follows from the Euler Homogeneous Function Theorem that $q \frac{\partial t(q, y)}{\partial q}+y \frac{\partial t(q, y)}{\partial y}=0$. Taking partial derivatives of the equation with respect to $q$ and $y$ respectively, we obtain $\frac{\partial t(q, y(q))}{\partial q}+$ $q \frac{\partial^{2} t(q, y(q))}{\partial q^{2}}=-y \frac{\partial^{2} t(q, y(q))}{\partial q \partial y}$ and $\frac{\partial t(q, y(q))}{\partial y}+q \frac{\partial^{2} t(q, y(q))}{\partial q \partial y}=-y \frac{\partial^{2} t(q, y(q))}{\partial y^{2}}$. Then, we have: $y^{\prime}(q)=-\frac{\frac{\partial t(q, y(q))}{\partial y}+q \frac{\partial^{2} t(q, y(q))}{q a \partial y}}{q \frac{\partial^{2} t(q, y(q))}{\partial y^{2}}}=-\frac{-\frac{\partial^{2} t(q, y(q))}{\partial y^{2}}}{q \frac{\partial^{2} t(q, y(q))}{\partial y^{2}}}=\frac{y}{q}>0$

Substituting $y(q)$ into $W\left(q, y, g^{*}\right)$ and $R\left(q, y, g^{*}\right),(5)$ and (7) can be rewritten as:

$$
\begin{aligned}
& \frac{\partial R\left(q_{1}, y_{1}, g^{*}\right)}{\partial q}=\frac{\partial R\left(q_{1}, y\left(q_{1}\right), g^{*}\right)}{\partial q}=\frac{\partial \overline{\bar{R}}\left(q_{1}, y\left(q_{1}\right)\right)}{\partial q}=0 \\
& \frac{\partial W\left(q_{0}, y_{0}, g^{*}\right)}{\partial q}=\frac{\partial W\left(q_{0}, y\left(q_{0}\right), g^{*}\right)}{\partial q}=\alpha \frac{\partial \overline{\bar{R}}\left(q_{0}, y\left(q_{0}\right)\right)}{\partial q}-q_{0} B^{\prime}\left(q_{0}\right)=0
\end{aligned}
$$

Considering $\lambda=1-\alpha$, we can rewrite (9) as:

$$
\frac{\partial \overline{\bar{R}}\left(q^{*}, y^{*}\right)}{\partial q}-q^{*} B^{\prime}\left(q^{*}\right)=\frac{\partial \overline{\bar{R}}\left(q^{*}, y\left(q^{*}\right)\right)}{\partial q}-q^{*} B^{\prime}\left(q^{*}\right)=0
$$

$\overline{\bar{R}}(q, y(q))$ is a strictly concave function. To see this, taking a second-order partial derivative of 
the function yields:

$$
\frac{\partial^{2} \overline{\bar{R}}(q, y(q))}{\partial q^{2}}=2 B^{\prime}(q)+q B^{\prime \prime}(q)<0
$$

Similarly, it can be shown that $\frac{\partial^{2} W(q, y(q), g)}{\partial q^{2}}=(2 \alpha-1) B^{\prime}(q)+(\alpha-1) q B^{\prime \prime}(q)<0$. Thus, both the private profit and social welfare functions, i.e., $R(q, y(q), g)$ and $W(q, y(q), g)$, are strictly concave in $q$.

From (18), $\frac{\partial \overline{\bar{R}}\left(q^{*}, y\left(q^{*}\right)\right)}{\partial q}=q^{*} B^{\prime}\left(q^{*}\right)<0$. It then follows readily that $q^{*}>q_{1}$ in view of $\frac{\partial \overline{\bar{R}}\left(q_{1}, y\left(q_{1}\right)\right)}{\partial q}=0$. Similarly, since $\frac{\partial W\left(q^{*}, y\left(q^{*}\right), g^{*}\right)}{\partial q}=(\alpha-1) q^{*} B^{\prime}\left(q^{*}\right)>0$, it follows readily that $q^{*}<q_{0}$ in view of $\frac{\partial W\left(q_{0}, y_{0}, g^{*}\right)}{\partial q}=0$, and that $W(q, y(q), g)$ is concave in $q$.

From (15), we also have $y_{1}<y^{*}<y_{0}$. Thus, parts (a) and (b) of Proposition 1 are proved.

As for the optimal toll rate, we have $p(q, y(q))=B(q)-\beta t(q, y(q))$. The derivative of this function with respect to $q$ is $\frac{\partial p(q, y(q))}{\partial q}=B^{\prime}(q)-\beta \frac{\partial t(q, y(q))}{\partial q}-\beta \frac{\partial t(q, y(q))}{\partial y} y^{\prime}(q)=B^{\prime}(q)<0$, which implies that the optimal toll is strictly decreasing with the optimal traffic demand. Consequently, the optimal toll rate for the BOT concession contract is strictly higher than the toll of the public road and strictly less than the toll of the private road under the symmetric cost information structure. The government sector sets a relatively lower toll for a public road in the interest of all road users, which result in higher traffic demand. Whereas, the toll charge for a private road is relatively higher due to the profit-seeking nature of the private investor, which will decrease traffic demand. The toll charge for the BOT road is set to balance road users' benefits and private profit, and thus lies between the private road toll and the public road toll.

It is also worth pointing out that the volume-capacity ratios in these three problems are the same, i.e., $\frac{q_{1}}{y_{1}}=\frac{q^{*}}{y^{*}}=\frac{q_{1}}{y_{1}}$, and thus the travel times are the same. From (6), (8) and (10) and the assumption that the travel time function is homogeneous of degree zero, we have $\left(\frac{q}{y}\right)^{2} \frac{d t\left(\frac{q}{y}\right)}{d\left(\frac{q}{y}\right)}=\frac{l}{\beta}$ for all three problems. The proof is similar to the one in previous studies for private toll roads (e.g., Xiao et al., 2007; Wu et al., 2011a). This property suggests that the BOT road offers the same service quality as the public and private roads.

Part (c) of Proposition 1 indicates that, under the symmetric cost information structure, the BOT 


\section{BOT Concession Contract Model under Asymmetric Cost Information}

In reality, concession contract negotiation involves more complex practice. Since a private investor always holds some private information, he may hide it to pursue more profit. The government often receives information from a private investor ex ante and has to judge whether it is truthful to be used as a basis to design a concession contract. The government also needs to closely monitor the performance of the BOT road to determine whether the private investor has complied with the contract. All these are caused by the information asymmetry between the government and the private investor.

In this paper, we focus on the cost information. As aforementioned, we assume $I(y)$ to be a common knowledge to both parties once the road capacity $y$ is determined. However, we consider that the government sector has incomplete information of the marginal maintenance $\operatorname{cost} \theta$ of the private investor before signing a concession contract.

From Proposition 1, a private investor, no matter what his value of $\theta$ is, would obtain the same profit $\tilde{P}$, if he reports his cost truthfully. If a private investor with $\theta_{0}$ overstates his marginal maintenance cost as $\theta_{1}\left(\theta_{1}>\theta_{0}\right)$, he will receive the corresponding BOT contract $\left(p^{*}\left(\theta_{1}\right), y^{*}\left(\theta_{1}\right), g^{*}\left(\theta_{1}\right)\right)$. Consequently, his actual profit will be: $q^{*}\left(\theta_{1}\right) B\left(q^{*}\left(\theta_{1}\right)\right)-$ $q^{*}\left(\theta_{1}\right) \beta t\left(q^{*}\left(\theta_{1}\right), y^{*}\left(\theta_{1}\right)\right)-\left[I\left(y^{*}\left(\theta_{1}\right)\right)+\theta_{1} q^{*}\left(\theta_{1}\right)\right]+g^{*}\left(\theta_{1}\right)+\left(\theta_{1}-\theta_{0}\right) q^{*}\left(\theta_{1}\right)=\tilde{P}+$ $\left(\theta_{1}-\theta_{0}\right) q^{*}\left(\theta_{1}\right)>\widetilde{P}$. Therefore, if we apply the symmetric information model in an asymmetric information situation, a private investor with a lower $\theta$ would gain a profit more than $\tilde{P}$ by intentionally misreporting a higher $\theta$. Should the investor truthfully reported his cost, the resulting optimal contract would be $\left(p^{*}\left(\theta_{0}\right), y^{*}\left(\theta_{0}\right), g^{*}\left(\theta_{0}\right)\right)$, which solves the BOT problem associated with the value of $\theta_{0}$. Because $\left(p^{*}\left(\theta_{1}\right), y^{*}\left(\theta_{1}\right), g^{*}\left(\theta_{1}\right)\right)$ is also the feasible solution to this problem, it will yield less social welfare than $\left(p^{*}\left(\theta_{0}\right), y^{*}\left(\theta_{0}\right), g^{*}\left(\theta_{0}\right)\right)$. In other words, such 
a misreporting reduces the weighted social welfare. It also reduces the consumers' surplus, i.e., $\int_{0}^{q} B(\omega) d \omega-q B(q)$, because the surplus increases with traffic demand, which decreases with $\theta$. Therefore, the symmetric information BOT model (4) should not be applied in an asymmetric information situation.

Instead, concession contract variables under asymmetric cost information should be set to maximize social welfare while covering the opportunity cost of a private investor and providing incentives to encourage the private investor to report his cost information truthfully. In general, misreporting is a type of principal-agent problems with hidden information, known as the adverse selection problem in the literature (Varian, 1992). A condition named as incentive compatibility (IC) can be introduced to tackle this type of problems. Herein, a process is incentive compatible if the private investor with any value of $\theta$ fares best when he truthfully reveals his cost information. Thus, the government should consider the IC condition to ensure the private investor to have no incentive to misreport his marginal maintenance cost and consequently determines an optimal combination of capacity choice, toll and guarantee as a function of the reported cost.

For modeling, we assume that the government sector has a subjective prior probability distribution for the unknown $\theta$ prior to receiving the cost reported by the private investor. Let $f(\theta)$ be the probability density function of $\theta$, which is continuous and strictly positive over the interval $\left[\theta_{0}, \theta_{1}\right]$. Let $F(\theta)$ be the cumulative distribution function of $\theta$. Considering that the design of optimal concession contracts under asymmetric information needs to be the function of the reported cost from the private investor, we denote the concession contract as $(q(\theta), y(\theta), g(\theta))$. If the true marginal maintenance cost of a private investor is $\theta$, and he reports it honestly, his profit from the BOT road will be:

$$
\begin{aligned}
R(\theta)=R(q(\theta) & , y(\theta), g(\theta))=\overline{\bar{R}}(q(\theta), y(\theta))+g(\theta) \\
& =q(\theta) B(q(\theta))-q(\theta) \beta t(q(\theta), y(\theta))-[I(y(\theta))+\theta q(\theta)]+g(\theta)
\end{aligned}
$$

However, if the private investor were to misreport his cost as $\hat{\theta}$, his profit would be:

$$
\begin{aligned}
& R(\hat{\theta}, \theta)=R(q(\hat{\theta}), y(\hat{\theta}), g(\hat{\theta}), \theta) \\
& \quad=q(\hat{\theta}) B(q(\hat{\theta}))-q(\hat{\theta}) \beta t(q(\hat{\theta}), y(\hat{\theta}))-[I(y(\hat{\theta}))+\theta q(\hat{\theta})]+g(\hat{\theta})
\end{aligned}
$$

To entice the private investor not to misreport his cost, we introduce an IC constraint as $R(\theta)=$ $R(\theta, \theta)=\max _{\widehat{\theta}} R(\hat{\theta}, \theta)$, for all $\theta$ in $\left[\theta_{0}, \theta_{1}\right]$. 
Simultaneously, the concession contract must also satisfy the IR constraint, i.e., $R(\theta) \geq \tilde{P}$, for all $\theta$ in $\left[\theta_{0}, \theta_{1}\right]$. Since the private investor has the same outside investment opportunities, we assume the same reservation level of utility under both information structures. As before, we still assume that the non-negative constraints of concession contract variables are not binding.

Hereinafter a concession contract $(q(\theta), y(\theta), g(\theta))$ is said to be feasible if and only if it satisfies both the IC and IR constraints.

We consider that the government attempts to design a BOT contract policy that maximizes the expected social welfare across all values of $\theta$ in $\left[\theta_{0}, \theta_{1}\right]$. The expected social welfare function $\widetilde{W}(q(\theta), y(\theta), g(\theta))$ can be defined as follows:

$$
\begin{gathered}
\widetilde{W}(q(\theta), y(\theta), g(\theta)) \\
=\int_{\theta_{0}}^{\theta_{1}}\left[\int_{0}^{q(\theta)} B(\omega) d \omega-q(\theta) B(q(\theta))-g(\theta)\right] f(\theta) d \theta+\alpha \int_{\theta_{0}}^{\theta_{1}} R(\theta) f(\theta) d \theta \\
=\int_{\theta_{0}}^{\theta_{1}}\left[\int_{0}^{q(\theta)} B(\omega) d \omega-q(\theta) \beta t(q(\theta), y(\theta))-I(y(\theta))-\theta q(\theta)\right. \\
-(1-\alpha) R(\theta)] f(\theta) d \theta
\end{gathered}
$$

The BOT contract problem under asymmetric cost information can thus be formulated as:

$$
\begin{aligned}
\max _{(q(\theta), y(\theta), g(\theta))} & \widetilde{W}(q(\theta), y(\theta), g(\theta)) \\
\text { s.t. } & R(\theta)=\max _{\widehat{\theta}} R(\hat{\theta}, \theta) \\
R(\theta) & \geq \tilde{P}
\end{aligned}
$$

We first state a lemma and then apply it to further transform the above BOT contract problem.

Lemma 1: A concession contract $(q(\theta), y(\theta), g(\theta))$ is incentive compatible if and only if it satisfies the following conditions for all $\theta$ in $\left[\theta_{0}, \theta_{1}\right]$ :
(a) $R^{\prime}(\theta)=-q(\theta)$;
(b) $q(\theta)$ is non-increasing in $\theta$. 
Proof: We first prove the "only if" part. From (21), for any $\theta$ and $\hat{\theta}$, we have:

$R(\theta) \geq R(\hat{\theta}, \theta)=R(\hat{\theta})+(\hat{\theta}-\theta) q(\hat{\theta})$

Swapping the roles $\theta$ and $\widehat{\theta}$ in (23) yields $R(\hat{\theta}) \geq R(\theta, \hat{\theta})=R(\theta)+(\theta-\hat{\theta}) q(\theta)$.

Thus, we have:

$$
(\hat{\theta}-\theta) q(\hat{\theta}) \leq R(\theta)-R(\hat{\theta}) \leq(\hat{\theta}-\theta) q(\theta)
$$

The above implies that $q(\theta)$ is non-increasing in $\theta$ and thus part (b) of Lemma 1 is proved.

Since $q(\theta)$ is a non-increasing and continuous function of $\theta$ in $\left[\theta_{0}, \theta_{1}\right]$, we have $R^{\prime}(\theta)=-q(\theta)$ for all $\theta \operatorname{in}\left[\theta_{0}, \theta_{1}\right]$ if we divide $(24)$ by $(\hat{\theta}-\theta)$ and take the limit as $\hat{\theta} \rightarrow \theta$. This completes the proof of the "only if" part.

We now prove the "if" part. From part (a) of Lemma 1, we have $R^{\prime}(\theta)=-q(\theta)$ and $q(\theta)$ is non-increasing, then $R(\theta)$ is a convex function of $\theta$. This implies that $R(\theta) \geq R(\hat{\theta})+$ $(\theta-\hat{\theta}) R^{\prime}(\hat{\theta})=R(\hat{\theta})+(\hat{\theta}-\theta) q(\hat{\theta})=R(\hat{\theta}, \theta)$. The equality comes from the above definition of $R(\hat{\theta}, \theta)$ and $R(\hat{\theta})$.Thus, $R(\theta)=\max _{\widehat{\theta}} R(\hat{\theta}, \theta)$. This completes the proof of Lemma 1 .

From part (a) of Lemma $1, R^{\prime}(\theta)$ is negative. Let $R^{* *}(\theta)$ be the profit resulted from the optimal solution to the BOT contract problem (20)-(22). By setting the optimal private profit under the largest $\theta$ to the reservation level $\widetilde{P}$, i.e., $R^{* *}\left(\theta_{1}\right)=\tilde{P}, R^{* *}(\theta)$ will be larger than $\tilde{P}$ for all $\theta$ in $\left[\theta_{0}, \theta_{1}\right)$. Based on Lemma 1 , this can be used to provide a characterization of the private profit function for a feasible concession contract. More specifically, the optimal private profit function can be expressed as follows:

$R^{* *}(\theta)=\tilde{P}+\int_{\theta}^{\theta_{1}} q^{* *}(\omega) d \omega$

According to Lemma 1, the BOT contract problem under asymmetric cost information (20)-(22) can be transformed into the following equivalent optimal control problem:

$$
\begin{aligned}
& \max _{(q(\theta), y(\theta), g(\theta))} \tilde{W}(q(\theta), y(\theta), g(\theta)) \\
& \text { s.t. } \quad R^{\prime}(\theta)=-q(\theta) \\
& R\left(\theta_{1}\right)=\tilde{P}
\end{aligned}
$$

Since the optimal control problem has a fixed end point and a free initial point, we can 
$\mu\left(\theta_{0}\right)=0$

$\frac{\partial L\left(q^{* *}(\theta), y^{* *}(\theta)\right)}{\partial q(\theta)}=$

$\left[B\left(q^{* *}(\theta)\right)-\beta t\left(q^{* *}(\theta), y^{* *}(\theta)\right)-q^{* *}(\theta) \beta \frac{\partial t\left(q^{* *}(\theta), y^{* *}(\theta)\right)}{\partial q(\theta)}-\theta\right] f(\theta)-\mu(\theta)=$

0

$\frac{\partial L\left(q^{* *}(\theta), y^{* *}(\theta)\right)}{\partial y(\theta)}=-\beta q^{* *}(\theta) \frac{\partial t\left(q^{* *}(\theta), y^{* *}(\theta)\right)}{\partial y(\theta)}-l=0$

$\delta R\left(\theta_{1}\right)$ in (30) means the deviation from the private profit with $\theta_{1}$. Since $R^{* *}\left(\theta_{1}\right)=\tilde{P}$, we choose $R\left(\theta_{1}\right)$ that satisfies $\delta R\left(\theta_{1}\right)>0$ to make sure $R\left(\theta_{1}\right)$ to be in the feasible region, thus we have $\mu\left(\theta_{1}\right) \geq 0$ from (29), which implies that $\mu\left(\theta_{1}\right)\left[R^{* *}\left(\theta_{1}\right)-\tilde{P}\right]=0$.

Integrating (27) and applying (28) and (29), we have $\mu(\theta)=(1-\alpha) F(\theta)$ for all $\theta$ in $\left[\theta_{0}, \theta_{1}\right]$.The co-state variable $\mu(\theta)$ can be viewed as the marginal cost of satisfying the IC constraint. The marginal cost equals zero for $\theta_{0}$ and increases with the reported $\theta$. A lower reported $\theta$ implies a smaller possibility of overstating the cost information by the private investor; therefore the government sector will have a lower marginal cost to implement this truth-telling mechanism. Meanwhile, we have $\mu\left(\theta_{1}\right)=(1-\alpha) F\left(\theta_{1}\right)=1-\alpha>0$, and $R^{* *}\left(\theta_{1}\right)=\tilde{P}$. This can be interpreted as that, since the government sector has the highest marginal cost to implement the IC constraint, the profit obtained by the private investor with the highest reported $\theta$ is kept at the reservation level via the corresponding guarantee set by the government sector.

Since $\mu(\theta)=(1-\alpha) F(\theta),(31)$ yields:

$\frac{\partial L\left(q^{* *}(\theta), y^{* *}(\theta)\right)}{\partial q(\theta)}$ 


$$
\begin{aligned}
=\left[B\left(q^{* *}(\theta)\right)\right. & \left.-\beta t\left(q^{* *}(\theta), y^{* *}(\theta)\right)-q^{* *}(\theta) \beta \frac{\partial t\left(q^{* *}(\theta), y^{* *}(\theta)\right)}{\partial q(\theta)}-\theta\right] f(\theta)-(1-\alpha) F(\theta) \\
& =0
\end{aligned}
$$

Then, we have

$$
\frac{\partial R\left(q^{* *}(\theta), y^{* *}(\theta), g^{* *}(\theta)\right)}{\partial q(\theta)}-q^{* *}(\theta) B^{\prime}\left(q^{* *}(\theta)\right)-(1-\alpha) \frac{F(\theta)}{f(\theta)}=0
$$

Since $R(\theta)$ is non-decreasing with $\theta$, we can derive $R\left(q^{* *}\left(\theta_{1}\right), y^{* *}\left(\theta_{1}\right), g^{* *}\left(\theta_{1}\right)\right)=\tilde{P}$ from setting corresponding $g^{* *}\left(\theta_{1}\right)$. We then infer $g^{* *}(\theta)$ from (27) as follows:

$$
\begin{gathered}
g^{* *}(\theta)=\beta q^{* *}(\theta) t\left(q^{* *}(\theta), y^{* *}(\theta)\right)+\theta q^{* *}(\theta)+I\left(y^{* *}(\theta)\right)-q^{* *}(\theta) B\left(q^{* *}(\theta)\right)+\widetilde{P} \\
+\int_{0}^{\theta_{1}} q^{* *}(\tilde{\theta}) d \widetilde{\theta}
\end{gathered}
$$

\section{Comparison and Discussion}

\subsection{Comparison of concession contracts}

In Section 2, the optimal concession contract of a BOT road under symmetric cost information is a series of independent contracts $\left(q^{*}, y^{*}, g^{*}\right)$ corresponding to a specific value of $\theta$. We explicitly denote it as $\left(q^{*}, y^{*}, g^{*} \mid \theta\right)$. We now compare it with the optimal concession contract policy with asymmetric cost information, i.e., $\left(q^{* *}(\theta), y^{* *}(\theta), g^{* *}(\theta)\right)$. Let $p^{*}\left(q^{*}, y^{*}, g^{*} \mid \theta\right)$

and $p^{* *}\left(q^{* *}(\theta), y^{* *}(\theta), g^{* *}(\theta)\right)$ be the optimal toll rate under symmetric and asymmetric cost information respectively and let $W\left(q^{* *}(\theta), y^{* *}(\theta), g^{* *}(\theta)\right)$ be the weighted social welfare under the asymmetric cost information for a specific $\theta \in\left[\theta_{0}, \theta_{1}\right]$.

Proposition 2. For any given $\theta$, we have
(a) $q^{* *}(\theta) \leq q^{*} ; y^{* *}(\theta) \leq y^{*}$;
(b) $R\left(q^{* *}(\theta), y^{* *}(\theta), g^{* *}(\theta)\right) \geq R\left(q^{*}, y^{*}, g^{*} \mid \theta\right)$; 
(c) $W\left(q^{* *}(\theta), y^{* *}(\theta), g^{* *}(\theta)\right) \leq W\left(q^{*}, y^{*}, g^{*} \mid \theta\right)$.

Proof: From (32), we can similarly infer that the optimal road capacity also increases in the optimal traffic demand under asymmetric information and the resulting volume-capacity ratio remains the same as the one under symmetric information. To facilitate the presentation, let $H(q, y(q))=\int_{0}^{q} B(\omega) d \omega-\beta q t(q, y(q))-q \theta-I(y(q))$, which is strictly concave in $q$.

Moreover, $\frac{\partial H(q, y(q))}{\partial q}=\frac{\partial \overline{\bar{R}}(q, y(q))}{\partial q}-q B^{\prime}(q)$. From (17) and (33), we infer that $\frac{\partial H\left(q^{* *}(\theta), y\left(q^{* *}(\theta)\right)\right)}{\partial q(\theta)} \geq \frac{\partial H\left(q^{*}, y\left(q^{*}\right) \mid \theta\right)}{\partial q}$, which implies that $q^{* *}(\theta) \leq q^{*}$ for any given $\theta$ over $\left[\theta_{0}, \theta_{1}\right]$.

Consequently, $y\left(q^{* *}(\theta)\right) \leq y\left(q^{*}\right)$. Thus, part (a) of Proposition 2 is proved.

Since the IR constraint (4) in the BOT problem under symmetric information is binding for any $\theta$ over $\left[\theta_{0}, \theta_{1}\right]$, the private investor obtains the reservation level of utility $\tilde{P}$, no matter what value of $\theta$ would be. Because the IR constraint (22) of the BOT problem under asymmetric information is slack over the interval $\left[\theta_{0}, \theta_{1}\right)$, the private profit is no less than reservation level $\tilde{P}$, for any given $\theta$. It is a special case that the private profit under asymmetric information equals that under symmetric information when the private investor reports his marginal maintenance cost to be the highest value, i.e. $R\left(q^{* *}\left(\theta_{1}\right), y^{* *}\left(\theta_{1}\right), g^{* *}\left(\theta_{1}\right)\right)=R\left(q^{*}, y^{*}, g^{*} \mid \theta_{1}\right)=\tilde{P}$. This completes the proof of part (b) of Proposition 2.

For part (c), we have

$$
\begin{gathered}
W\left(q^{* *}(\theta), y\left(q^{* *}(\theta)\right), g^{* *}(\theta)\right) \\
=\int_{0}^{q^{* *}(\theta)} B(\omega) d \omega-q^{* *}(\theta) \beta t\left(q^{* *}(\theta), y^{* *}(\theta)\right)-I\left(y^{* *}(\theta)\right)-\theta q^{* *}(\theta) \\
\quad-(1-\alpha) R\left(q^{* *}(\theta), y^{* *}(\theta), g^{* *}(\theta)\right) \\
=H\left(q^{* *}(\theta), y\left(q^{* *}(\theta)\right)\right)-(1-\alpha) \tilde{P}-(1-\alpha) \int_{\theta}^{\theta_{1}} q(\tilde{\theta}) d \tilde{\theta} \\
W\left(q^{*}, y\left(q^{*}\right), g^{*} \mid \theta\right)=\int_{0}^{q^{*}} B(\omega) d \omega-q^{*} \beta t\left(q^{*}, y^{*}\right)-I\left(y^{*}\right)-\theta q^{*}-(1-\alpha) R\left(q^{*}, y^{*}, g^{*} \mid \theta\right) \\
=H\left(q^{*}, y\left(q^{*}\right) \mid \theta\right)-(1-\alpha) \tilde{P}
\end{gathered}
$$


Since $\frac{\partial H(q, y(q))}{\partial q}=\frac{\partial \overline{\bar{R}}(q, y(q))}{\partial q}-q B^{\prime}(q), \frac{\partial \overline{\bar{R}}\left(q^{*}, y\left(q^{*}\right)\right)}{\partial q}-q^{*} B^{\prime}\left(q^{*}\right)=0$ suggests that $\left(q^{*}, y^{*}\right)$ is the maximizer of $H(q, y(q))$. Thus, for any given $\theta$, we have $H\left(q^{*}, y^{*} \mid \theta\right) \geq H\left(q^{* *}(\theta), y^{* *}(\theta)\right)$. Since $(1-\alpha) \int_{\theta}^{\theta_{1}} q(\tilde{\theta}) d \tilde{\theta} \geq 0$ over the interval $\left[\theta_{0}, \theta_{1}\right]$, we have $H\left(q^{* *}(\theta), y^{* *}(\theta)\right)-$ $(1-\alpha) \tilde{P}-(1-\alpha) \int_{\theta}^{\theta_{1}} q(\tilde{\theta}) d \tilde{\theta} \leq H\left(q^{*}, y^{*}\right)-(1-\alpha) \tilde{P}$. Part (c) of Proposition 2 is thus proved. $\square$

Proposition 2 verifies that the optimal concession contract under symmetric cost information is not desirable for the government when the private investor's marginal maintenance cost is unknown, because it does not satisfy the IC constraint (21), i.e., the private investor has incentive to misreport his true cost. Specifically, from (17) and (33), the optimal choice of $p^{* *}(\theta), y^{* *}(\theta)$ and $g^{* *}(\theta)$ are chosen as if the government were to determine the symmetric-information solution to $(1-\alpha) \frac{F(\theta)}{f(\theta)}$ rather than to zero. If the government has a full information about the cost, the optimal solution to the BOT problem is to set the concession contract variables to keep the "one and only" private profit level, i.e., $\tilde{P}$, for all $\theta$ over $\left[\theta_{0}, \theta_{1}\right]$. However, the optimal solution to the BOT problem under asymmetric information indicates that the private investor obtains information rent by owning his private information, which is reflected by the fact that the private profit is higher than the reservation level $\tilde{P}$ for all $\theta$ over $\left[\theta_{0}, \theta_{1}\right)$. Since $R(\theta)$ is a nonincreasing function in reported $\theta$, a private investor with a lower reported $\theta$ obtains a higher private profit, which make the private investor with a lower true $\theta$ have no incentive to overstate his cost. He has no incentive to understate his cost either. Otherwise the IC constraint would not be satisfied.

We now turn our attention to the optimal toll charges under both information structures. From (17), we have:

$$
p^{*}\left(q^{*}, y\left(q^{*}\right), g^{*} \mid \theta\right)=q^{*} \beta \frac{\partial t\left(q^{*}, y\left(q^{*}\right)\right)}{\partial q}+\theta
$$

The above suggests that the optimal toll charge under symmetric information is the marginal cost of this BOT road including the marginal travel time cost and marginal maintenance cost. From (33), we have:

$$
p^{* *}\left(q^{* *}(\theta), y\left(q^{* *}(\theta)\right), g^{* *}(\theta)\right)=q^{* *}(\theta) \beta \frac{\partial t\left(q^{* *}(\theta), y\left(q^{* *}(\theta)\right)\right)}{\partial q}+\theta+(1-\alpha) \frac{F(\theta)}{f(\theta)}(38)
$$

This implies that, in addition to the marginal cost of this BOT road, the asymmetric-information toll includes one additional component, i.e., $(1-\alpha) \frac{F(\theta)}{f(\theta)}$, which can be interpreted as the marginal cost of dealing with misreporting due to information asymmetry. From (37) and (38), 
the optimal tolls are both independent of the government guarantee. Note that $q \beta \frac{\partial t(q, y)}{\partial q}=$ $\frac{\partial t\left(\frac{q}{y}\right)}{\partial\left(\frac{q}{y}\right)}\left(\frac{q}{y}\right)$. Since the volume-capacity ratios are the same for both information structures, we have $p^{* *}\left(q^{* *}(\theta), y\left(q^{* *}(\theta)\right)\right) \geq p^{*}\left(q^{*}, y\left(q^{*}\right) \mid \theta\right)$ due to $(1-\alpha) \frac{F(\theta)}{f(\theta)} \geq 0$.

From the above analysis, we have $p^{* *}\left(q^{* *}(\theta), y^{* *}(\theta)\right)-p^{*}\left(q^{*}, y^{*} \mid \theta\right)=(1-\alpha) \frac{F(\theta)}{f(\theta)}$, which indicates that the difference between the optimal tolls under two information structures is resulted from the marginal cost of information asymmetry. Given that the term $(1-\alpha) \frac{F(\theta)}{f(\theta)}$ is decreasing in $\alpha$, the asymmetric-information toll is closer to the symmetric-information toll when parameter $\alpha$ becomes large. Meanwhile, the difference between optimal tolls increases with the value of reported $\theta$ since $(1-\alpha) \frac{F(\theta)}{f(\theta)}$ is increasing in $\theta$. These suggest that the toll difference diminishes when the government sector pays more attention to the producer's surplus or the private investor reports a smaller $\theta$.

We now compare the government guarantee. If $\overline{\bar{R}}\left(q^{* *}(\theta), y^{* *}(\theta)\right) \leq \overline{\bar{R}}\left(q^{*}, y^{*} \mid \theta\right)$, we must have $g^{* *}(\theta) \geq g^{*}$ due to the fact that $R\left(q^{* *}(\theta), y^{* *}(\theta), g^{* *}(\theta)\right) \geq R\left(q^{*}, y^{*}, g^{*} \mid \theta\right)$ from Proposition 2. However, if $\overline{\bar{R}}\left(q^{* *}(\theta), y\left(q^{* *}(\theta)\right)\right)>\overline{\bar{R}}\left(q^{*}, y\left(q^{*}\right) \mid \theta\right)$, the asymmetric-information guarantee can be lower than the symmetric-information guarantee, i.e., $g^{* *}(\theta) \leq g^{*}$. For further investigation, note that the volume-capacity ratios are the same for both information structures. Integrating on both sides of Equation (15), we have $y(q)=b q$, where $b$ is a constant coefficient. Incorporating $y(q)$ into the project profit function yields $\overline{\overline{\mathrm{R}}}(q, y(q))=[p(q, y(q))-\theta-l b] q$. Subsequently, $\frac{\partial \overline{\bar{R}}(q, y(q))}{\partial q}=[p(q, y(q))-\theta-l b]-\frac{1}{\left|E_{p}\right|}$, where $\left|E_{p}\right|$ denotes the price elasticity of traffic demand for the BOT road. Since the first component of the marginal project profit, i.e., $p(q, y(q))-\theta-l b$, is positive, the sign of the marginal project profit will depend on the value of $\left|E_{p}\right|$. Specifically, if the price elasticity is small, the project profit decreases with $q$, and thus $\overline{\bar{R}}\left(q^{* *}(\theta), y\left(q^{* *}(\theta)\right)\right)>\overline{\bar{R}}\left(q^{*}, y\left(q^{*}\right) \mid \theta\right)$. Otherwise, the project profit increases with $q$ and thus $\overline{\bar{R}}\left(q^{* *}(\theta), y^{* *}(\theta)\right) \leq \overline{\bar{R}}\left(q^{*}, y^{*} \mid \theta\right)$. 
The tuition behind this reflects the impact of the asymmetric-information-toll being set to be higher than the symmetric-information-toll. If the price elasticity is low, the higher toll rate can be viewed as a reward for the private investor, and thus $\overline{\bar{R}}\left(q^{* *}(\theta), y^{* *}(\theta)\right)>\overline{\bar{R}}\left(q^{*}, y^{*} \mid \theta\right)$. In this case, the government sector needs to provide less guarantee to prevent the private investor from obtaining excess information rent. Whereas, if the price elasticity is high, a higher toll rate would yield $\overline{\bar{R}}\left(q^{* *}(\theta), y^{* *}(\theta)\right) \leq \overline{\bar{R}}\left(q^{*}, y^{*} \mid \theta\right)$, and then the government sector must reward the private investor by offering more guarantee to prevent the private investor from misreporting.

We now consider the case when $\theta=\theta_{0}$. In this case, we have $(1-\alpha) \frac{F(\theta)}{f(\theta)}=0$, and thus $p^{* *}\left(\theta_{0}\right)=p^{*}, y^{* *}\left(\theta_{0}\right)=y^{*}$ and $q^{* *}\left(\theta_{0}\right)=q^{*}$, which suggests that the government sets the same toll rate and road capacity for the private investor with the lowest reported $\theta$ under both information structures. This also yields the same project profit, i.e., $\overline{\bar{R}}\left(q^{* *}\left(\theta_{0}\right), y^{* *}\left(\theta_{0}\right)\right)=$ $\overline{\bar{R}}\left(q^{*}, y^{*} \mid \theta_{0}\right)$. From Proposition 2(b), we know $R\left(q^{* *}\left(\theta_{0}\right), y^{* *}\left(\theta_{0}\right), g^{* *}\left(\theta_{0}\right)\right)>R\left(q^{*}, y^{*}, g^{*} \mid \theta_{0}\right)$. Therefore, $g^{* *}\left(\theta_{0}\right)>g^{*}$, suggesting that the government sector must reward the private investor with more guarantee for honestly reporting his cost.

\subsection{Comparative static analysis of asymmetric-information concession contract}

Information rent. From Part (b) of Proposition 2, the private profit under asymmetric information is greater than the symmetric-information private profit, which is the reservation level $\tilde{P}$. The difference between private profits under two information structures, named information rent, is resulted from information asymmetry. Let $\mathrm{R}_{\mathrm{IR}}$ denotes the information rent. Then from Proposition 1 and (25), we have $R_{I R}=R\left(q^{* *}(\theta), y^{* *}(\theta), g^{* *}(\theta)\right)-R\left(q^{*}, y^{*}, g^{*} \mid \theta\right)=\int_{\theta}^{\theta_{1}} q^{* *}(\omega) d \omega$, which decreases with $\theta$. That is to say, the private investor with a lower marginal maintenance cost will be allowed to gain more information rent than the one with a higher marginal maintenance cost, which can be viewed as a reward for not overstating his cost. Since there is no need to reward the private investor with the highest reported $\theta$, his information rent equals zero.

Optimal toll, road capacity and government guarantee. From Lemma $1, q^{* *}(\theta)$ is nonincreasing with $\theta$. Thus, $p^{* *}\left(q^{* *}(\theta), y\left(q^{* *}(\theta)\right)\right)$ is non-decreasing with $\theta$ due to $\frac{\partial p(q, y(q))}{\partial q}=$ $B^{\prime}(q)<0$ in Section 2. Since the optimal road capacity is increasing with the optimal traffic demand, we can infer the optimal road capacity $y^{* *}(\theta)$ is non-increasing with $\theta$. As the 

when the reported $\theta$ is strictly higher than its minimum level, it would set a higher toll rate and a lower road capacity.

We now investigate how the government guarantee varies with $\theta$. From Lemma 1, we have $R^{* * \prime}(\theta)=-q^{* *}(\theta)<0$. Note that $\frac{\partial R\left(q^{* *}(\theta), y\left(q^{* *}(\theta)\right), g^{* *}(\theta)\right)}{\partial \theta}=\frac{\partial \overline{\bar{R}}\left(q^{* *}(\theta), y\left(q^{* *}(\theta)\right)\right)}{\partial \theta}+g^{* *^{\prime}}(\theta)=$ $-q^{* *}(\theta)<0$, and thus how the optimal government guarantee $g^{* *}(\theta)$ varies with $\theta$ depends on the monotonicity of the optimal project profit function $\overline{\bar{R}}\left(q^{* *}(\theta), y\left(q^{* *}(\theta)\right)\right)$. That is, $g^{* *^{\prime}}(\theta)$ must be negative if $\frac{\partial \overline{\bar{R}}\left(q^{* *}(\theta), y\left(q^{* *}(\theta)\right)\right)}{\partial \theta} \geq 0$, and $g^{* * \prime}(\theta)$ may be positive if $\frac{\partial \overline{\bar{R}}\left(q^{* *}(\theta), y\left(q^{* *}(\theta)\right)\right)}{\partial \theta}<0$. For further investigation, we have:

$$
\begin{aligned}
\frac{\partial \overline{\bar{R}}\left(q^{* *}(\theta), y\left(q^{* *}(\theta)\right)\right)}{\partial \theta} & =\frac{\partial \overline{\bar{R}}\left(q^{* *}(\theta), y\left(q^{* *}(\theta)\right)\right)}{\partial q(\theta)} q^{* *^{\prime}}(\theta) \\
& =\left[p^{* *}\left(q^{* *}(\theta), y\left(q^{* *}(\theta)\right)\right)\left(1-\frac{1}{\left|E_{p^{* *}}\right|}\right)-\theta-l b\right] q^{* * \prime}(\theta)
\end{aligned}
$$

Obviously, the sign of (39) depends on the price elasticity of traffic demand for the BOT road since $q^{* * \prime}(\theta) \leq 0$. Consider the special case that $\frac{\partial \overline{\bar{R}}\left(q^{* *}(\theta), y\left(q^{* *}(\theta)\right)\right)}{\partial q(\theta)}=0$, with which we define $p^{* *}(\theta)=p_{1}, q^{* *}(\theta)=q_{1},\left|E_{p^{* *}}\right|=\left|E_{p_{1}}\right|=\frac{p_{1}\left(q_{1}, y\left(q_{1}\right)\right)}{p_{1}\left(q_{1}, y\left(q_{1}\right)\right)-\theta-l b}$.

When $\left|E_{p^{* *}}\right| \leq\left|E_{p_{1}}\right|$, the travel demand is less elastic and we have $\frac{\partial \overline{\bar{R}}\left(q^{* *}(\theta), y\left(q^{* *}(\theta)\right)\right)}{\partial \theta} \geq 0$, and $\mathrm{g}^{* *}(\theta)$ must be decreasing with $\theta$. When $\left|E_{p^{* *}}\right|>\left|E_{p_{1}}\right|, \frac{\partial \overline{\bar{R}}\left(q^{* *}(\theta), y\left(q^{* *}(\theta)\right)\right)}{\partial \theta}<0, \mathrm{~g}^{* *}(\theta)$ may increase with $\theta$.

To understand these results, observe that the optimal toll rate is increasing with the reported $\theta$. If the price elasticity of traffic demand for the BOT road is small, this pricing policy can be viewed as a punishment for a lower reported $\theta$, because the project profit would be lower. Consequently, the government needs to provide more guarantee to reward a lower reported $\theta$ so that the private investor with a low $\theta$ is willing to report his cost truthfully.

We now examine the impact of the weighting factor $\alpha$ associated with the producer's surplus. Note that $\frac{\partial H\left(q^{* *}(\theta), y\left(q^{* *}(\theta)\right)\right)}{\partial q(\theta)}=(1-\alpha) \frac{F(\theta)}{f(\theta)} \geq 0$, and thus $\frac{\partial H\left(q^{* *}(\theta), y\left(q^{* *}(\theta)\right)\right)}{\partial q(\theta)}$ is decreasing with $\alpha$. 
Since $H(q(\theta), y(q(\theta)))$ is concave function of $q(\theta), \frac{\partial H\left(q^{* *}(\theta), y\left(q^{* *}(\theta)\right)\right)}{\partial q(\theta)}$ is decreasing with $q^{* *}(\theta)$. It can be inferred that $q^{* *}(\theta)$ and thus $y^{* *}(\theta)$ are increasing with $\alpha$, which implies the optimal toll under asymmetric information is decreasing with $\alpha$.

Welfare loss. Part (c) of Proposition 2 suggests that the society suffers a loss of weighted social welfare due to information asymmetry. Let $\mathrm{W}_{\mathrm{LO}}$ denotes the welfare loss. From (35) and (36), we have:

$W_{L O}=\left[H\left(q^{*}, y\left(q^{*}\right) \mid \theta\right)-H\left(q^{* *}(\theta), y\left(q^{* *}(\theta)\right)\right)\right]+(1-\alpha) \int_{\theta}^{\theta_{1}} q^{* *}(\omega) d \omega$

As stated, the weighted welfare loss can be divided into two parts: the difference between the social welfare functions under two information structures and the weighted information rent.

It is a special case when $\theta=\theta_{0}, \theta=\theta_{1}$ or $\alpha=1$. Because of the fact that the government sets the same toll rate and road capacity to the private investor who reports $\theta_{0}$ under two information structures, we have $H\left(q^{*}, y\left(q^{*}\right) \mid \theta_{0}\right)-H\left(q^{* *}\left(\theta_{0}\right), y\left(q^{* *}\left(\theta_{0}\right)\right)\right)=0$. Then, $\mathrm{W}_{\mathrm{LO}}=$ $(1-\alpha) \int_{\theta_{0}}^{\theta_{1}} q(\omega) d \omega$, which indicates the welfare loss is only cuased by the information rent when contracting with private investor with the lowest reported $\theta$. Since the information rent equals zero when $\theta=\theta_{1}$, we have $W_{L O}=H\left(q^{*}, y\left(q^{*}\right) \mid \theta_{1}\right)-W_{\alpha=1}\left(q^{* *}\left(\theta_{1}\right), y\left(q^{* *}\left(\theta_{1}\right)\right)\right)$, which indicates that the welfare loss is only caused by the difference between the social welfare under two information structures. Meanwhile, we have $\mathrm{q}^{*}=\mathrm{q}^{* *}(\theta)$ when $\alpha=1$ from the proof of Proposition 2, which means the first term of (40) equals zero. Since the second term is also equals zero when $\alpha=1$, there is no welfare loss when the government sector pays equal attention to both the consumer's surplus and producer's surplus.

To investigate the impact of $\theta$ on welfare loss, we derive the partial derivative of the first term with respect to $\theta$ as follows: $\frac{\partial\left[H\left(q^{*}, y\left(q^{*}\right) \mid \theta\right)-H\left(q^{* *}(\theta), y\left(q^{* *}(\theta)\right)\right)\right]}{\partial \theta}=\frac{\partial \mathrm{H}\left(q^{*}, y\left(q^{*}\right) \mid \theta\right)}{\partial \mathrm{q}} \mathrm{q}^{*^{\prime}}(\theta)+$ $\frac{\partial \mathrm{H}\left(q^{*}, y\left(q^{*}\right) \mid \theta\right)}{\partial \mathrm{y}} \mathrm{y}^{\prime}\left(q^{*}\right) \mathrm{q}^{* \prime}(\theta)-\frac{\partial \mathrm{H}\left(q^{* *}(\theta), y\left(q^{* *}(\theta)\right)\right)}{\partial \mathrm{q}(\theta)} \mathrm{q}^{* * \prime}(\theta)-\frac{\partial \mathrm{H}\left(q^{* *}(\theta), y\left(q^{* *}(\theta)\right)\right)}{\partial \mathrm{y}(\theta)} \mathrm{y}^{* * \prime}\left(q^{* *}(\theta)\right) \mathrm{q}^{* * \prime}(\theta)$. From the optimal conditions of the symmetric-information and asymmetric-information models, we have $\frac{\partial \mathrm{H}\left(q^{*}, y\left(q^{*}\right) \mid \theta\right)}{\partial \mathrm{q}}=0, \frac{\partial \mathrm{H}\left(q^{*}, y\left(q^{*}\right) \mid \theta\right)}{\partial \mathrm{y}}=0, \frac{\partial \mathrm{H}\left(\mathrm{q}^{* *}(\theta), \mathrm{y}\left(\mathrm{q}^{* *}(\theta)\right)\right)}{\partial \mathrm{y}(\theta)}=0$ and $\frac{\partial \mathrm{H}\left(\mathrm{q}^{* *}(\theta), \mathrm{y}\left(\mathrm{q}^{* *}(\theta)\right)\right)}{\partial \mathrm{q}(\theta)}=$ $(1-\alpha) \frac{\mathrm{F}(\theta)}{\mathrm{f}(\theta)} \geq 0$. Then, we have $\frac{\partial\left[H\left(q^{*}, y\left(q^{*}\right) \mid \theta\right)-H\left(q^{* *}(\theta), y\left(q^{* *}(\theta)\right)\right)\right]}{\partial \theta}=-\frac{\partial \mathrm{H}\left(\mathrm{q}^{* *}(\theta), \mathrm{y}^{* *}(\theta)\right)}{\partial \mathrm{q}(\theta)} \mathrm{q}^{* * \prime}(\theta) \geq$ 0 since $\mathrm{q}^{* * \prime}(\theta) \leq 0$ from Lemma 1 . Thus, the first term of (40) is increasing with the reported $\theta$. Since the second term of (40) is the weighted information rent that decreases with $\theta$, we infer that the monotonicity of the welfare loss depends on the trade-off between these two terms. 
Decision rules. The difference between the optimal concession contracts under two information structures is important for the government when contracting with a private investor. Under asymmetric information, when the reported $\theta$ from the private investor is strictly larger than the minimum level $\theta_{0}$, the government can set a lower road capacity than the symmetric-information counterpart, which decreases with the reported $\theta$, and specify a higher toll, which increases with the reported $\theta$. The value of the government guarantee depends on the price elasticity of traffic demand for the BOT road. The policy $\left(\mathrm{q}^{* *}(\theta), \mathrm{y}^{* *}(\theta), \mathrm{g}^{* *}(\theta)\right)$ will result in information rent that decreases with the reported $\theta$ and yield a welfare loss.

\section{Numerical Example}

Consider $B(q)=10-2 q ; t(q, y)=1+\frac{q}{y} ; \beta=1 ; c(q, y)=4 y+\theta q$ and $\alpha=0.5$. Let $\theta$ follow a uniform distribution over $\left[\theta_{0}, \theta_{1}\right]$. We then have $f(\theta)=\frac{1}{\theta_{1}-\theta_{0}}, F(\theta)=\frac{\theta-\theta_{0}}{\theta_{1}-\theta_{0}}$ and $\frac{F(\theta)}{f(\theta)}=\theta-\theta_{0}$. Furthermore, the private profit and social welfare can be expressed as:

$R(q, y, g)=-2 q^{2}-\frac{q^{2}}{y}+(9-\theta) q-4 y+g$ and $W(q, y, g)=-\frac{0.5 q^{2}}{y}+0.5(9-\theta) q-2 y-$ $0.5 \mathrm{~g}$.

Thus, the BOT problem under symmetric cost information is

$$
\begin{aligned}
& \max _{(q, y, g)}-\frac{0.5 q^{2}}{y}+0.5(9-\theta) q-2 y-0.5 g \\
& \text { s.t. }-2 q^{2}-\frac{q^{2}}{y}+(9-\theta) q-4 y+g \geq \tilde{P} .
\end{aligned}
$$

According to the optimality conditions, the KKT multiplier $\lambda$ equals $1-\alpha$, i.e., 0.5 . The optimal traffic demand, road capacity and government guarantee are $q^{*}=\frac{5-\theta}{2}, y^{*}=\frac{5-\theta}{4}$ and $g^{*}=\tilde{P}$ while the optimal toll rate is $p^{*}=2+\theta$. Thus, the optimal social welfare is $W\left(q^{*}, y^{*}, g^{*} \mid \theta\right)=$ $0.25(5-\theta)^{2}-0.5 \tilde{P}$ and the optimal private profit is $R\left(q^{*}, y^{*}, g^{*} \mid \theta\right)=\tilde{P}$, which means that the revenue of the BOT road just covers its amortized construction and maintenance cost and the profit of private investor is from the government guarantee that is at the reservation level.

The BOT problem under asymmetric cost information is 
From (32) to (34), the optimal solution will be $q^{* *}(\theta)=\frac{5+0.5 \theta_{0}-1.5 \theta}{2}{ }^{2,} ; y^{* *}(\theta)=\frac{5+0.5 \theta_{0}-1.5 \theta}{4}$ and $g^{* *}(\theta)=\frac{3}{4} \theta^{2}-\frac{3}{4}\left(5+0.5 \theta_{0}\right) \theta-\frac{1}{8}\left(\theta_{1}-\theta_{0}\right)\left(3 \theta_{1}+\theta_{0}\right)+\frac{5}{4}\left(2 \theta_{1}+\theta_{0}\right)+\tilde{P}$, and the optimal toll rate is $p^{* *}(\theta)=2+1.5 \theta-0.5 \theta_{0}$.

Thus, the optimal private profit is $R\left(q^{* *}(\theta), y^{* *}(\theta), g^{* *}(\theta)\right)=\left(\theta_{1}-\theta\right) \frac{\left(10+\theta_{0}-1.5 \theta_{1}-1.5 \theta\right)}{4}+\tilde{P}$, showing that the private investor obtains the reservation level $\tilde{P}$ when his marginal maintenance $\operatorname{cost}$ is $\theta_{1}$, and his information rent increases as $\theta$ decreases. The optimal social welfare for a given $\theta$ is $W\left(q^{* *}(\theta), y^{* *}(\theta), g^{* *}(\theta)\right)=-\left(\frac{5+0.5 \theta_{0}-1.5 \theta}{2}-\frac{5-\theta}{2}\right)^{2}+\frac{(5-\theta)^{2}}{4}-0.5 \tilde{P}-$ $0.5\left(\theta_{1}-\theta\right) \frac{\left(10+\theta_{0}-1.5 \theta_{1}-1.5 \theta\right)}{4}$, suggesting that the government achieves the highest social welfare when contracting with the private investor with the lowest $\theta$ since $W\left(q^{* *}(\theta), y^{* *}(\theta), g^{* *}(\theta)\right)$ is decreasing with $\theta$.

Comparing it with the optimal solution to the BOT problem under symmetric information, we can verify the results in Proposition 2, i.e. $q^{* *}(\theta)=\frac{5-\theta+0.5\left(\theta_{0}-\theta\right)}{2} \leq \frac{5-\theta}{2}=q^{*}, y^{* *}(\theta)=$ $\frac{5-\theta+0.5\left(\theta_{0}-\theta\right)}{4} \leq \frac{5-\theta}{4}=y^{*}$ and $p^{* *}(\theta)=2+\theta+0.5\left(\theta-\theta_{0}\right) \geq 2+\theta=p^{*}$.

Owing to the private information, the private investor obtains extra information rent beyond the reservation level $\tilde{P}$. According to the above calculations, the information rent is:

$$
R\left(q^{* *}(\theta), y^{* *}(\theta), g^{* *}(\theta)\right)-R\left(q^{*}, y^{*}, g^{*} \mid \theta\right)=\left(\theta_{1}-\theta\right) \frac{\left(10+\theta_{0}-1.5 \theta_{1}-1.5 \theta\right)}{4}
$$

\footnotetext{
${ }^{2}$ Considering the non-negativity of optimal traffic demand under symmetric and asymmetric cost information, we assume $\theta_{0}<\theta_{1} \leq \frac{10+\theta_{0}}{3}$
} 

higher information rent, and the information rent approaches to zero as $\theta$ approaches $\theta_{1}$. Meanwhile, the government suffers from a welfare loss due to its inferior position for the cost information. The loss of social welfare for a given $\theta$ is

$$
\begin{aligned}
W\left(q^{* *}(\theta), y^{* *}(\theta), g^{* *}(\theta)\right)-W\left(q^{*}, y^{*}, g^{*} \mid \theta\right) \\
=-\left(\frac{5+0.5 \theta_{0}-1.5 \theta}{2}-\frac{5-\theta}{2}\right)^{2}-0.5\left(\theta_{1}-\theta\right) \frac{\left(10+\theta_{0}-1.5 \theta_{1}-1.5 \theta\right)}{4}
\end{aligned}
$$

Thus the loss increases with $\theta$, implying that the government suffers from a greater welfare loss when contracting with a private investor with a higher $\theta$ under asymmetric cost information.

In addition, we have $q^{* *}\left(\theta_{0}\right)=q^{*}, p^{* *}\left(\theta_{0}\right)=p^{*}$ and $y^{* *}\left(\theta_{0}\right)=y^{*}$ when $\theta=\theta_{0}$, implying that the private investor with the lowest value of $\theta$ accepts the same toll rate and capacity provided by the government sector under two information structures; whereas he obtains the highest information rent, i.e., $\left(\theta_{1}-\theta_{0}\right) \frac{\left(10-1.5 \theta_{1}-0.5 \theta_{0}\right)}{4}$, which means $g^{* *}(\theta)>g^{*}$ when $\theta=\theta_{0}$. Owing to $\alpha=0.5<1$, the loss of social welfare is the half of the information rent.

\section{Conclusions}

Previous studies on concession contracts of BOT roads typically focus on the choice of toll and capacity under a symmetric rather than asymmetric information structure. Because the government hardly possesses complete information about the marginal maintenance costs of private investors in practice, this paper proactively accommodates such information asymmetry in designing optimal BOT contracts. Recognizing the government guarantee as an essential variable to a BOT concession contract, and considering the weighting factor of the producer's surplus is strictly lower than that of consumers' surplus, we explicitly regard a concession contract as a combination of three critical variables, i.e., toll rate, capacity choice and government guarantee. We examine how a concession contract of a BOT road should be designed to maximize social welfare, while allowing for a reservation level of utility to the private investor and inducing him to report truthfully his private information. Under symmetric information, an optimal contract will make the private profit to be the reservation level no matter what the marginal maintenance cost would be. However, under asymmetric information, since the private investor has incentive to misreport his cost to gain additional profit, a concession contract policy with a combination of three variables corresponding to the reported cost parameter $\theta$ is used to hedge against the uncertainty associated with the cost information from the government's perspective. The policy provides the private investor extra information rent, which decreases with the reported marginal maintenance cost. Correspondingly, the government 

and the weighting factor of the producer's surplus. With the properties of the optimal policy well established, we provide a strategy for the government sector to ensure the signing of an optimal concession contract during the contract negotiation process when the cost information is unknown. The private investor is required to charge a toll higher than the symmetric-information toll and build this BOT road with a capacity less than the symmetric-information capacity. To induce the private investor not to misreport his cost information, the optimal toll should be set to be increasing in the reported cost and the optimal capacity should be set to be decreasing in the reported cost, while the amount of the government guarantee will depend on whether traffic demand is elastic or not.

In reality, the welfare loss and information rent resulted from information asymmetry will induce the government to search for information. The model considered in this paper is unilateral information asymmetry, while a strategic information searching behavior of the government generally takes place in the contract negotiation process. Thus, our future research will integrate such information searching behavior into the BOT concession problem under asymmetric information. We will also consider the information asymmetries with respect to both construction and maintenance costs as well as information uncertainty caused by, e.g., uncertain traffic demand.

\section{Acknowledgements}

The authors wish to thank the two anonymous reviewers for their constructive comments. Yafeng Yin would like to acknowledge the supported by grants from the National Science Foundation (CMMI-1362631; EFRI-1441231) and the National Natural Science Foundation of China (71228101).

\section{References}

Ashuri, B., Kashani, H., Molenaar, K.R., Lee, S., and Lu, J.,2012. Risk-neutral pricing approach for evaluating BOT highway projects with government minimum revenue guarantee options. Journal of construction engineering and management, 138(4), 545-557.

Auriol E. and Picard P.M., 2013. A theory of BOT concession contracts. Journal of economic behavior and organization, 89, 187-209.

Bailey, E.E., 1976. Innovation and regulation: a reply. Journal of public economics, 5, 393-394.

Baron, D.P. and Myerson, R.B., 1982. Regulating a monopolist with unknown costs. Econometrica, 50(4), 911-930.

Bolton, P. and Dewatripont, M., 2005. Contract theory. Cambridge, London: The MIT Press. Bower, R.S., 1981. Discussion. Journal of finance, 36, 397-399.

Chen, A., Subprasom, K., and Ji, Z., 2003. Mean-variance model for the build-operate-transfer 
Chiang, A.C., 1992. Elements of dynamic optimization. McGraw Hill Higher Education Publishing Co.

de Palma, A., Lindsey, R., Proost, S., 2007. Investment and the use of tax and toll revenues in the transport sector: the research agenda. Research in transportation economics, 19, 1-26.

Engel, E., Fischer, R., and Galetovic, A., 2001. Least-present-value -of-revenue auctions and highway franchising. Journal of political economy, 109(5), 993-1020.

George, A.A., 1970. The market for 'lemons': quality uncertainty and the market mechanism. The quarterly journal of economics, 84(3), 488-500.

Gunter, J.Z. and Alberto, B., 1999. Performance specified road maintenance contracts- The road to the future- The Latin American perspective. XXIst world road congress, Kuala Lumpur.

Guo, X. and Yang, H., 2005. The price of anarchy of Cournot oligopoly. Lecture notes in computer science, 3828, 246-257.

Guo,X. and Yang, H., 2009. Analysis of a build-operate-transfer scheme for road franchising. International journal of sustainable transportation, 3, 312-338

Nombela, G. andRus, G., 2004. Flexible-term contracts for road franchising. Transportation research part A: policy and practice, 38(3), 163-179.

Kamien, M.I. and Schwartz, N.L., 1991. Dynamic optimization: The calculus of variations and optimal control in economics and management (2nd edition). New York: North-Holland Publishing Co.

Laffont, J.J. and Martimort, D., 2002. The theory of incentives: the principal-agent model. Princeton, New Jersey: Princeton University Press.

Michael, A.P.T., Michelle, L.P., 2014. Investigating the impact of maintenance regimes on the design life of road pavements in a changing climate and the implications for transport policy. Transport policy, 41, 117-135.

Mills, G., 1995. Welfare and profit divergence for a tolled link in a road network. Journal of transport economics and police, 29, 137-146.

Small, K.A., Winston, C. and Evans, C.A., 1989. Road works. The Brookings Institution, Washington D.C.

Subprasom,K. and Chen A., 2007. Effects of regulation on highway pricing and capacity choice of a build-operate-transfer Scheme. Journal of construction engineering and management, 133(1), 64-71.

Tan, Z., Yang, H. and Guo, X., 2009. Build-operate-transfer schemes for road franchising with road deterioration and maintenance effects. Transportation and traffic theory 2009: Golden Jubilee, Springer, 241-261.

Tan, Z., Yang, H., Guo, X., 2010. Properties of Pareto-efficient contracts and regulations for road franchising. Transportation research part B: methodological, 44(4), 415-433.

Tan, Z. and Yang, H., 2012. Flexible build-operate-transfer contracts for road franchising under demand uncertainty. Transportation research part B: methodological, 46(10), 1419-1439.

Ubbels, B. andVerhoef, E.T., 2008. Auctioning concessions for private roads. Transportation research part A: policy and practice, 42(1), 155-172. 
Varian, H.R., 1992. Microeconomic analysis. New York: W.W. Norton\& Company, Inc.

Vassallo, J.M., 2010. The role of the discount rate in tendering highway concessions under the LPVR approach. Transportation research part A: policy and practice, 44(10), 806-814.

Verhoef, E. T., 2007. Second-best road pricing through highway franchising. Journal of urban economics, 62(2), 337-361.

Viton, P. A., 1995. Private roads. Journal of urban economics, 37, 260-289.

Wang, S., Meng, Q. and Liu, Z. (2013) Fundamental properties of volume-capacity ratio of a private toll road in general networks. Transportation research part B, 47, 77-86.

Wu, D., Yin, Y., and Yang, H. (2011a). The independence of volume-capacity ratio of private toll roads in general networks. Transportation research part B, 45(1), 96-101.

Wu, D., Yin, Y., and Yang, H. (2011b). Optimal selection of build-operate-transfer projects on transportation networks. Transportation research part B, 45(10), 1699-1709.

Xiao, F., Yang, H., and Han, D. (2007). Competition and efficiency of private toll roads. Transportation research part B, 41 (3), 292-308.

Yang, H., and Meng, Q., 2000. Highway pricing and capacity choice in a road network under a build-operate-transfer scheme. Transportation research part A: policy and practice, 34(3), 207-222.

Yang, H., and Meng, Q., 2002. A note on highway pricing and capacity choice in a road network under a build-operate-transfer scheme. Transportation research part A: policy and practice, 36(7), 659-663.

Ziya, S., Ayhan, H. and Foley, R.D., 2004. Relationships among three assumptions in revenue management. Operations research, 52(5), 804-809. 